Goldschmidt 2021 Abstract

https://doi.org/10.7185/gold2021.5741

\section{U-Pb geochronology at 100ppm age uncertainty}

PROF. URS SCHALTEGGER, PHD ${ }^{1}$, MARIA

OVTCHAROVA $^{2}$, SEAN P GAYNOR ${ }^{1}$, BLAIR SCHOENE ${ }^{3}$, JÖRN-FREDERIK WOTZLAW ${ }^{4}$, JOSHUA H.F.L. DAVIES ${ }^{5}$, FEDERICO FARINA $^{6}$ AND DR. NICOLAS DAVID GREBER $^{7}$

${ }^{1}$ University of Geneva

${ }^{2}$ Dept. of Earth Sciences, University of Geneva

${ }^{3}$ Princeton University

${ }^{4}$ ETH Zürich

${ }^{5}$ Université de Québec à Montréal

${ }^{6}$ Università degli Studi di Milano

${ }^{7}$ University of Bern

Presenting Author: urs.schaltegger@unige.ch

High-precision zircon $\mathrm{U}-\mathrm{Pb}$ dating using chemical-abrasion isotope-dilution thermal ionization mass spectrometry (CA-IDTIMS) using the EARTHTIME tracer is considered the "gold standard" of geochronology. Practitioners of this technique are constantly striving for higher precision and accuracy ages. Precise and reliable $\mathrm{U}-\mathrm{Pb}$ ages are used for diverse geological questions, ranging from determining correlative/causal relationships between geological processes, as well as to quantify the geological timescale. These applications require complete understanding of the analytical precision, within-lab repeatability, and inter-lab reproducibility. Therefore, it is crucial for the high precision $\mathrm{U}-\mathrm{Pb}$ community to establish that analytical variance is smaller than the targeted temporal resolution. To understand the variance within the Geneva high precision TIMS U-Pb lab, we generated a large dataset of synthetic EARTHTIME ET100 and ET2Ga solution measurements, as well as of age determinations of natural zircon reference materials Temora- 2 and GJ-1, analyzed between 2008 and 2021. We conducted the measurements with two different TIMS mass spectrometers (a Thermo Triton, and an IsotopX Phoenix). From these data we conclude the following:

(1) The choice of the TIMS platform used for age determination is not a limiting factor for precision and repeatability. Precision of $100 \mathrm{ppm}$ or better for ${ }^{206} \mathrm{~Pb} /{ }^{238} \mathrm{U}$ dates can be achieved when samples are measured at the same time on both mass spectrometers.

(2) We observed excess scatter in ET100 solution data, likely due to incomplete spike-sample equilibration during preparation; this can be mitigated by additional preparation steps to achieve adequate sample-spike equilibration.

(3) Analyses of Temora-2 and GJ-1 reference zircon materials show significant excess scatter. This scatter is due to incomplete $\mathrm{Pb}$-loss mitigation, mixing of autocrystic with antecrystic or xenocrystic domains. Our proposed mean age values for these reference materials are five to ten times less precise than ET100 solution dates.

(4) Repeated measurement of the ET100 solution is the best way to check repeatability of a U-Pb geochronology lab at the $100 \mathrm{ppm}$ level of a ${ }^{206} \mathrm{~Pb} /{ }^{238} \mathrm{U}$ age, if it is prepared correctly.
Natural materials do not reproduce at the same level, mainly due to the combination of natural age variation, inheritance and the potential of residual lead loss. 